\title{
Accelerated intermittent theta burst as a substitute for patients needing electroconvulsive therapy during the COVID-19 pandemic: study protocol for an open-label clinical trial
}

Daniel M. Blumberger*1,2; Zafiris J. Daskalakis ${ }^{1,2,3}$; Fidel Vila-Rodriguez ${ }^{4}$; David BoivinLafleur $^{1,2}$; Michelle S. Goodman ${ }^{1}$; Tyler Kaster ${ }^{1,2}$; Yuliya Knyahnytska ${ }^{1,2}$; Gerasimos Konstantinou $^{1,2}$; Alisson P. Trevizol ${ }^{1,2}$; Daphne Voineskos ${ }^{1,2}$; Cory R. Weissman ${ }^{1,2}$; Jonathan Downar ${ }^{2,5}$

${ }^{1}$ Temerty Centre for Therapeutic Brain Intervention, Centre for Addiction and Mental Health, 1001 Queen St West, Toronto, ON M6J 1H4, Canada

${ }^{2}$ Department of Psychiatry, University of Toronto, 563 Spadina Crescent, Toronto, ON M5S 2 J7, Canada ${ }^{3}$ Department of Psychiatry, University of California San Diego, 9500 Gilman Drive, La Jolla, CA, 92161, USA

${ }^{4}$ Non-Invasive Neurostimulation Therapies Laboratory, Department of Psychiatry, University of British Columbia, 2255 Wesbrook Mall, Vancouver, BC V6T 2A1, Canada

${ }^{5}$ Krembil Research Institute and Centre for Mental Health, University Health Network, 60 Leonard Ave, Toronto, ON M5T 0S8, Canada

Corresponding author:

Dr. Daniel M. Blumberger

1001 Queen St. W., Unit 4-115, Toronto, ON, Canada M6J1H4

email daniel.blumberger@,camh.ca 
medRxiv preprint doi: https://doi.org/10.1101/2020.12.15.20248260; this version posted December 17, 2020. The copyright holder for this preprint (which was not certified by peer review) is the author/funder, who has granted medRxiv a license to display the preprint in

It is made available under a CC-BY-NC-ND 4.0 International license .

\begin{abstract}
Background: Treatment resistant depression (TRD) is one of the leading causes of disability in Canada and is associated with significant societal costs. Repetitive transcranial magnetic stimulation (rTMS) is an approved, safe, and well-tolerated intervention for TRD. In the setting of the COVID-19 pandemic, reducing the number of visits to the clinic is a potential approach to significantly minimize exposure and transmission risks to patients. This can be accomplished by administering multiple treatment sessions in a single day, using an rTMS protocol known as accelerated intermittent theta burst stimulation (aiTBS). The objective of this novel study is to assess the feasibility, acceptance and clinical outcomes of a practical high-dose aiTBS protocol, including tapering treatments and symptom-based relapse prevention treatments, in patients with unipolar depression previously responsive to electroconvulsive therapy (ECT) or patients warranting ECT due to symptom severity.
\end{abstract}

Methods: All patients with unipolar depression referred to the brain stimulation service at the Centre for Addiction and Mental Health (CAMH) who warrant ECT will be offered screening to assess for eligibility to enroll in this trial. This open label, single group trial consists of 3 phases. In the acute treatment phase, treatment will occur 8 times daily for 5 days a week, until symptom remission is achieved or a maximum of 10 days of treatment. In the tapering phase, treatments will be reduced to 2 treatment days per week for 2 weeks, followed by 1 treatment day per week for 2 weeks. Patients will then enter the symptom-based relapse prevention phase including virtual check-ins and a treatment schedule based on symptom level. Remission, response and change in scores on several clinical measures from baseline to the end of the acute, tapering and relapse prevention phases represent the clinical outcomes of interest.

Discussion: Findings from this novel clinical trial may provide support for the use of aiTBS, including tapering treatments and symptom-based relapse prevention treatments, as a safe and effective alternative intervention for patients needing ECT during the COVID-19 pandemic.

Trial registration: Clinicaltrials.gov: NCT04384965

Keywords: repetitive Transcranial Magnetic Stimulation (rTMS), accelerated intermittent theta burst stimulation (aiTBS), treatment resistant depression (TRD), COVID-19 
medRxiv preprint doi: https://doi.org/10.1101/2020.12.15.20248260; this version posted December 17, 2020. The copyright holder for this preprint (which was not certified by peer review) is the author/funder, who has granted medRxiv a license to display the preprint in

It is made available under a CC-BY-NC-ND 4.0 International license

\section{Introduction}

\section{Background, rationale and objectives}

Major depressive disorder (MDD) is a highly prevalent and disabling disorder associated with substantial societal costs (1). Among Neurological, Mental, and Substance Use disorders, MDD is the number one cause of disability worldwide (2). In Ontario, Canada alone, $\$ 12.5$ billion a year is attributed to mood disorderrelated costs (3). The magnitude of the social, health, and economic burden of MDD reflects, to a large degree, the limited effectiveness of our current treatment options. Treatment-resistant depression (TRD) is defined as failure to respond to at least 2 adequate antidepressant trials (4) - a distressingly common problem. Electroconvulsive therapy (ECT) achieves remission rates of $65-75 \%$ in TRD $(5,6)$, but is hampered by significant cognitive adverse effects (7-9), public stigma (10), and the need for anesthesia, limiting its use to $<1 \%$ of TRD cases (11). In the setting of the COVID-19 pandemic, access to ECT will likely be even lower due to restriction in volumes related to enhanced infection control procedures.

Repetitive transcranial magnetic stimulation (rTMS) is an evidence-based treatment for TRD. It involves stimulation of cortical neurons using externally applied, powerful, focused magnetic field pulses to induce lasting changes in the activity of brain regions involved in regulating thoughts, emotions, and behavior (1214). Stimulation is applied non-invasively, over the scalp, using a handheld magnetic coil (15). Unlike with $\mathrm{ECT}$, treatment does not require seizure induction, anesthesia, or the accompanying necessary manual ventilation that can aerosolize respiratory droplets, which is a major concern due to the COVID-19 pandemic.

rTMS is approved as a treatment for MDD by both Health Canada (2002) and the US Food and Drug Administration (FDA) (2008). The standard rTMS protocol for TRD, approved by the FDA, by far the most widely used across North America, involves applying $10 \mathrm{~Hz}$ stimulation to the left dorsolateral prefrontal cortex (DLPFC). Treatment consists of 3000 pulses delivered over a period of 37.5 minutes (16) and can last between four to six weeks, totaling 20 to 30 daily sessions per patient. In the setting of the COVID-19 pandemic, reducing the number of visits to the clinic is important to minimize exposure and transmission 
medRxiv preprint doi: https://doi.org/10.1101/2020.12.15.20248260; this version posted December 17, 2020. The copyright holder for this preprint (which was not certified by peer review) is the author/funder, who has granted medRxiv a license to display the preprint in

It is made available under a CC-BY-NC-ND 4.0 International license .

risk to patients. This can be accomplished by administering multiple treatment sessions on a single day, an approach known as accelerated rTMS. This protocol allows patients to receive a complete course of rTMS with fewer clinic visits (though each visit lasts a day) overall. In effect, this protocol cohorts patients into smaller groups receiving treatment at the same time.

Recently, our research teams achieved considerable gains in improving rTMS cost-effectiveness by reducing the time required per session and conducted the landmark trial that led to FDA approval of intermittent theta burst stimulation (iTBS) (17). As opposed to standard rTMS, iTBS uses $50 \mathrm{~Hz}$ bursts of stimulation and can be administered in $1 / 10^{\text {th }}$ of the time of high frequency rTMS ( $\sim 3 \mathrm{~min}$ vs. $\left.37.5 \mathrm{~min}\right)$, yet achieves similar reductions in depressive symptom burden (18). An accelerated protocol with multiple daily brief iTBS sessions could enable patients to achieve remission more rapidly and reduce time of direct contact with others. Thus, the clinical potential of accelerated iTBS (aiTBS) protocols in patients who would otherwise get ECT is substantial.

Several recently published studies have demonstrated that accelerated rTMS can achieve similar outcomes to once daily rTMS treatment in only 4 to 10 days $(19,20)$. A recent study found that applying 2 sessions per day for 10 days in 28 participants resulted in 56\% response and 37\% remission (21). A similar study applied 5 sessions per day for 4 days and achieved 35\% response and 15\% remission in 20 participants (22). More recently, researchers published a case series demonstrating that a 5-day regimen of 10x daily iTBS sessions is not only safe and tolerable but yields substantially higher remission rates than conventional once-daily rTMS (i.e., $>70 \%$ remission on all measures) (23). Notably, this case series included patients who had previously failed to respond to once daily rTMS. Another study by researchers at Stanford University used the same treatment regimen and included patients with highly refractory MDD who did not respond to traditional high frequency rTMS and failed to respond to an acute course of ECT. Five of six participants responded to treatment, and four participants were in full remission at the final treatment session (24). Of note, these protocols $(23,24)$ include functional Magnetic Resonance Imaging (fMRI) imaging and a 
medRxiv preprint doi: https://doi.org/10.1101/2020.12.15.20248260; this version posted December 17, 2020. The copyright holder for this preprint (which was not certified by peer review) is the author/funder, who has granted medRxiv a license to display the preprint in

It is made available under a CC-BY-NC-ND 4.0 International license

complicated algorithm to refine the treatment target location. Such procedures using neuroimaging guidance are neither feasible nor practical during a pandemic.

Unfortunately, in both of the latter studies, the response to treatment was not consistently maintained. Cole and colleagues reported that 6 of 21 participants underwent a second course after they no longer met remission criteria (23), and Williams and colleagues reported that by 4 weeks after treatment end, participants no longer met response criteria (24). Taken together, these findings suggest that while accelerated iTBS (aiTBS) may be a safe, well-tolerated, and effective treatment option, there is a clear need for continued investigation into maintaining response and remission rates following the acute intervention. As such, the primary objective of this study is to assess the feasibility, acceptance, and clinical outcomes of a practical high-dose aiTBS protocol, including tapering treatments and symptom-based relapse prevention treatments, in patients with MDD either previously responsive to ECT or those needing ECT due to symptom severity.

\section{Methods}

\section{Study Design}

All patients referred for ECT at the Centre for Addiction and Mental Health (CAMH) in Toronto, Canada, will be assessed by one of the brain stimulation psychiatrists as part of current clinical procedures. Suitable patients will be referred for virtual screening via a hospital approved videoconferencing software by a research analyst (RA). Prior to the screening visit, participants will be provided a link to a read-only copy of the consent form. The consent discussion will be conducted virtually, or over the telephone if the participant declines videoconferencing. Following the consent discussion, research personnel will obtain the participant's informed e-consent to participate in the trial, using REDCap. If a prospective participant does not have access to internet/email/technology, they may come in-person to CAMH to give consent virtually, using our tablet or computer, or a paper copy can be mailed to them. 
medRxiv preprint doi: https://doi.org/10.1101/2020.12.15.20248260; this version posted December 17, 2020. The copyright holder for this preprint (which was not certified by peer review) is the author/funder, who has granted medRxiv a license to display the preprint in

It is made available under a CC-BY-NC-ND 4.0 International license.

Weekly follow-up assessments, including clinical rating scale assessments and self-report questionnaires, will be conducted virtually via videoconferencing with a physician backup to the RA available at all times.

Figure 1. Flow diagram for the study design

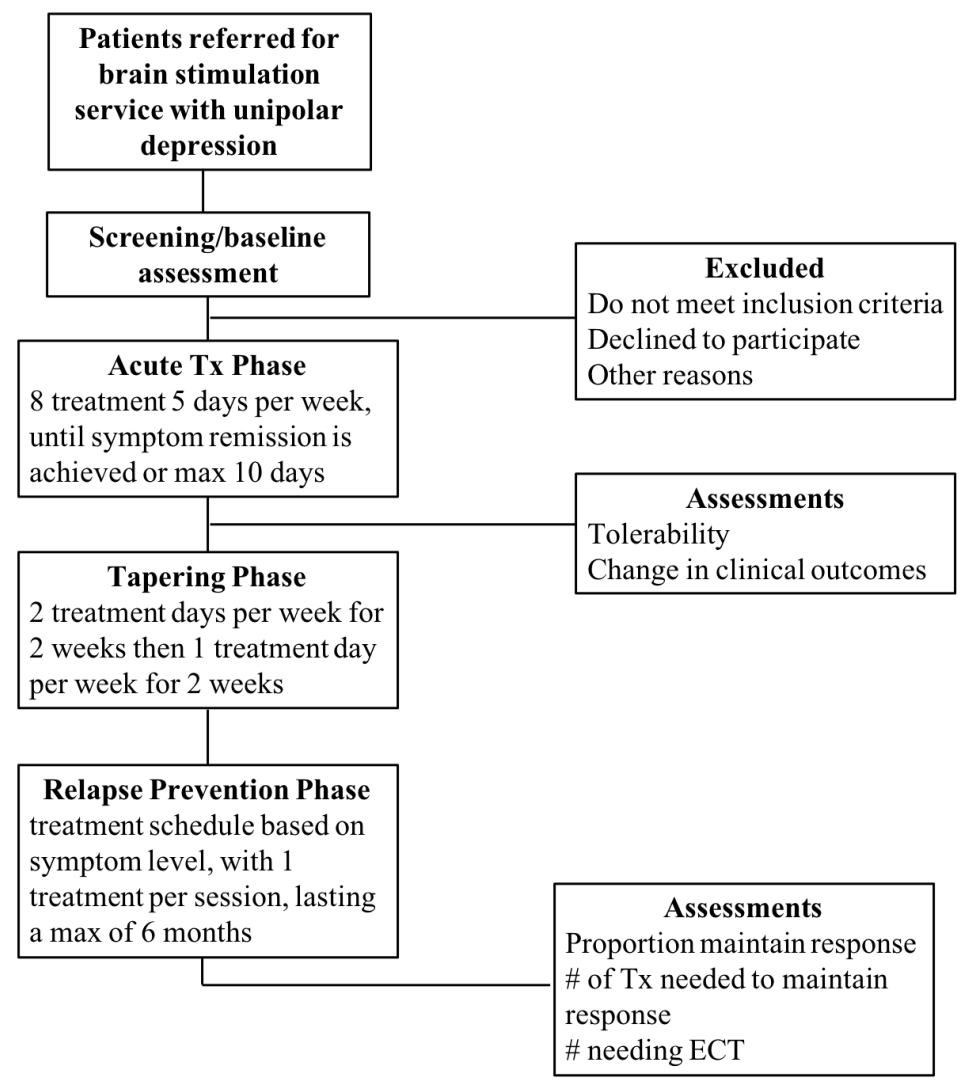

In the acute treatment phase, treatment will occur 8 times daily (50 min pause between treatments) on weekdays, until symptom remission is achieved (Hamilton Rating Scale for Depression, 24 item (HRSD-24) score $\leq$ to 10 ) or a maximum of 10 working days of daily treatment. In the tapering phase, treatments will be reduced to 2 days per week for 2 weeks and then 1 day per week for 2 weeks ( 4 weeks total). Patients who have an insufficient response after a minimum of 5 treatment days and maximum of 16 treatment days (i.e. the end of tapering phase) based on less than a 50\% reduction in HRSD-24 from the screening visit and the clinical opinion of the brain stimulation psychiatrist, will be discontinued from the trial. Patients who have responded (minimum of 50\% reduction in HRSD-24 scores) to treatment will enter the symptom-based relapse prevention phase including virtual check-in with the RA and a treatment schedule based on symptom level and clinician judgement. This modified relapse prevention algorithm, known as the STABLE 
medRxiv preprint doi: https://doi.org/10.1101/2020.12.15.20248260; this version posted December 17, 2020. The copyright holder for this preprint (which was not certified by peer review) is the author/funder, who has granted medRxiv a license to display the preprint in It is made available under a CC-BY-NC-ND 4.0 International license.

algorithm, was developed to prevent relapse after a successful course of ECT (25). The relapse prevention phase will last a maximum of 6 months, consistent with prior ECT relapse prevention studies, and will include rescue treatment days ( 8 sessions per day) based on symptom re-emergence and clinician judgment. (see Table 1). Each treatment session across all phases of the study will consist of a single iTBS treatment, delivering 600 pulses of iTBS (bursts of 3 pulses at $50 \mathrm{~Hz}$, bursts repeated at $5 \mathrm{~Hz}$, with a duty cycle of 2 seconds on, 8 seconds off, over 20 cycles / 3 minutes) at a target of $110 \%$ of the subject's resting motor threshold (RMT). This protocol involves minimal contact ( $3 \mathrm{~min}$ ) between technician and patients.

Technicians will follow local infection prevention and control (IPAC) recommendations regarding personal protective equipment and room cleaning. rTMS treatments will be conducted in person with added safety and cleaning precautions. Research staff will be wearing a mask, face shield, and gloves during any in-person interactions and will maintain a physical distance from patients whenever possible. In addition, all individuals will undergo screening for COVID-19 symptoms and contacts and will be provided with a mask, prior to entering CAMH each day. Any person who is found to have symptoms or contacts as per the screening protocol (known as a positive screen) will not be permitted to enter CAMH and treatment will not be allowed to continue that day. These cases will be reviewed by IPAC at CAMH to inform if, and when, treatment can continue. 
medRxiv preprint doi: https://doi.org/10.1101/2020.12.15.20248260; this version posted December 17, 2020. The copyright holder for this preprint (which was not certified by peer review) is the author/funder, who has granted medRxiv a license to display the preprint in

It is made available under a CC-BY-NC-ND 4.0 International license

Table 1. Study Phases and Relapse Prevention Algorithm

\begin{tabular}{|c|c|c|c|}
\hline \multicolumn{4}{|c|}{ Weeks 1-2: Acute Treatment Phase } \\
\hline \multicolumn{4}{|c|}{ Daily treatment ( $8 \mathrm{tx} /$ day) for up to 10 days } \\
\hline \multicolumn{4}{|c|}{ Weeks 3-6: Tapering Treatment Phase } \\
\hline & Weeks 3-4 & \multicolumn{2}{|c|}{$\begin{array}{c}2 \text { treatment days ( } 8 \text { tx/day) per week for } 2 \\
\text { weeks }\end{array}$} \\
\hline & Weeks 5-6 & \multicolumn{2}{|c|}{$\begin{array}{c}1 \text { treatment day (8 tx/day) per week for } 2 \\
\text { weeks }\end{array}$} \\
\hline \multicolumn{4}{|c|}{ Weeks 6-30: Symptom-Driven Relapse Prevention Algorithm Treatment Phase } \\
\hline $\begin{array}{c}\text { Treatment } \\
\text { days per week }\end{array}$ & Description & $\begin{array}{c}\begin{array}{c}\text { Corresponding HRSD-24 } \\
\text { ratings }\end{array} \\
\end{array}$ & $\begin{array}{l}\text { Relapse } \\
\text { Potential }\end{array}$ \\
\hline \multirow{3}{*}{0} & $\begin{array}{l}\text { Current symptom level very } \\
\text { low }\end{array}$ & $\begin{array}{l}\text { Current HRSD-24 score } \leq \\
6\end{array}$ & \multirow{3}{*}{ Low } \\
\hline & $\begin{array}{l}\text { Current symptom level low } \\
\text { to moderate, } \\
\text { with only small drift from } \\
\text { baseline level }\end{array}$ & $\begin{array}{l}\text { Current HRSD- } 24 \text { score } 7 \text { - } \\
12 \text { and } \leq 2 \text { points higher } \\
\text { than baseline }\end{array}$ & \\
\hline & $\begin{array}{l}\text { Last two HRSD-24 scores in } \\
\text { remitted range } \\
\text { with a flat trajectory } \\
\text { (remission stable with less } \\
\text { than 2-point change from } \\
\text { previous) }\end{array}$ & $\begin{array}{l}\text { Current HRSD-24 score } 7- \\
10 \text { and previous score } 5-10 \\
\text { and current score is } \leq 2 \\
\text { points higher than previous } \\
\text { score or score is } \leq 2 \text { points } \\
\text { higher than end of tapering } \\
\text { score if not a remitter }\end{array}$ & \\
\hline \multirow[b]{2}{*}{2} & $\begin{array}{l}\text { Current symptom level very } \\
\text { high }\end{array}$ & $\begin{array}{l}\text { Current HRSD-24 score } \geq \\
16\end{array}$ & \multirow[b]{2}{*}{ High } \\
\hline & $\begin{array}{l}\text { Current symptom level } \\
\text { moderate to high, with } \\
\text { trajectory increasing rapidly } \\
\text { and large drift from baseline }\end{array}$ & $\begin{array}{l}\text { Current HRSD-24 score } 11 \\
-15, \text { and current score is } \geq \\
3 \text { points higher than } \\
\text { previous score, and current } \\
\text { score is } \geq 8 \text { points higher } \\
\text { than end of tapering score }\end{array}$ & \\
\hline 1 & $\begin{array}{l}\text { Patients not requiring } 0 \text { or } 2 \\
\text { treatments receive } 1 \\
\text { treatment }\end{array}$ & $\begin{array}{l}\text { Current HRSD-24 score } \\
\text { intermediate between } \\
\text { criteria for low or high } \\
\text { relapse potential }\end{array}$ & Moderate \\
\hline
\end{tabular}

\section{Clinical Measures}

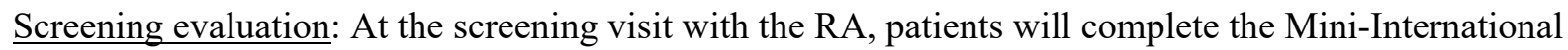
Neuropsychiatric Interview (MINI). This scale assesses current and lifetime MDD and other psychiatric disorders and it will be used to clarify psychiatric inclusion and exclusion criteria. The Antidepressant 
medRxiv preprint doi: https://doi.org/10.1101/2020.12.15.20248260; this version posted December 17, 2020. The copyright holder for this preprint (which was not certified by peer review) is the author/funder, who has granted medRxiv a license to display the preprint in

It is made available under a CC-BY-NC-ND 4.0 International license .

Treatment History Form (ATHF) will be used to collect information on previous anti-depressant treatment resistance. A detailed history of any prior ECT and rTMS treatment will be collected. The Transcranial Magnetic Stimulation Adult Safety Screen (TASS) will be used to assess potential rTMS safety risk factors. Patients will also complete baseline clinical measures including Hamilton Rating Scale for Depression (HRSD-24), Beck Depression Inventory (BDI-II), the Patient Health Questionnaire (PHQ-9), the Scale of Suicidal Ideation (SSI), the Generalized Anxiety Disorder 7-Item (GAD-7), and the World Health Organization Disability Assessment Schedule (WHODAS).

Clinical Assessments During Treatment: Depressive symptoms will be assessed using BDI-II (each treatment) and the HRSD-24 and the SSI (weekly). Hospital mandated assessments including the PHQ-9 and GAD-7 will be completed weekly and the WHODAS will be completed at the end of acute, tapering and relapse prevention phases. The clinician global impression severity (CGI-S) and improvement (CGI-I) scores will ve assessed by the most responsible physician. Remission, response and change in scores on the BDI-II, HRSD-24, GAD-7, PHQ-9 and SSI from baseline to the end of the acute, tapering and relapse prevention phases will be clinical outcomes of interest.

Regarding telephone assessments, two items on the HRSD-24 which pertain to the visual assessment of psychomotor retardation and agitation (i.e. Items 8 and 9) are not able to be completed. Therefore, these items will be scored as "0" and the clinical rater will document that the above items could not be rated. For self-report questionnaires completed at virtual assessment visits, the study personnel will complete the questionnaires with participants by: (1) reading the questions and answers verbatim to the participant and documenting their answers, (2) virtually sharing their screen so that the participant can read the questions and provide the answers, or (3) the research staff will send a link via REDCap to the participant to fill out the questionnaires on their own device.

If a participant reports worsening of symptoms or suicidal ideation or report adverse events that may require further investigation due to safety reasons, the study investigator or delegate will contact the participant for 
medRxiv preprint doi: https://doi.org/10.1101/2020.12.15.20248260; this version posted December $17,2020$. The copyright holder for this preprint (which was not certified by peer review) is the author/funder, who has granted medRxiv a license to display the preprint in

It is made available under a CC-BY-NC-ND 4.0 International license .

follow-up. If a participant reports feeling unsafe due to suicidal thoughts or requires medical attention, study personnel will advise to contact 911 or go to the nearest Emergency Room. All adverse events will be assessed and reported accordingly. If a participant unexpectedly drops off a virtual session, they will be called immediately to ensure there is no safety concern. The emergency contact will be contacted in case of emergency or an inability to contact the participant after they unexpectedly drop off a virtual session.

Table 2: Schedule of Events

\begin{tabular}{|c|c|c|c|c|c|c|c|c|c|c|}
\hline \multirow{3}{*}{ Measure } & \multicolumn{10}{|c|}{ Study Period } \\
\hline & \multirow[t]{2}{*}{$\begin{array}{l}\text { Screening } \\
\text { (Baseline) }\end{array}$} & \multicolumn{3}{|c|}{ Acute Tx Phase } & \multicolumn{3}{|c|}{ Tapering Tx Phases } & \multicolumn{3}{|c|}{$\begin{array}{c}\text { Relapse Prevention Tx } \\
\text { Phase }\end{array}$} \\
\hline & & Every Tx & $\begin{array}{l}\text { Weekly/ } \\
\text { Disconti } \\
\text { nuation }\end{array}$ & $\begin{array}{l}\text { End/ } \\
\text { Discontin } \\
\text { uation }\end{array}$ & $\begin{array}{l}\text { Every } \\
\text { Tx }\end{array}$ & $\begin{array}{l}\text { Weekly/ } \\
\text { Disconti } \\
\text { nuation }\end{array}$ & $\begin{array}{l}\text { End/ } \\
\text { Discontin } \\
\text { uation }\end{array}$ & $\begin{array}{l}\text { Every } \\
\text { Tx }\end{array}$ & $\begin{array}{l}\text { Weekly/ } \\
\text { Disconti } \\
\text { nuation }\end{array}$ & $\begin{array}{l}\text { End/ } \\
\text { Discontin } \\
\text { uation }\end{array}$ \\
\hline Informed Consent & $\mathrm{X}$ & & & & & & & & & \\
\hline MINI & $\mathrm{X}$ & & & & & & & & & \\
\hline TASS & $\mathrm{X}$ & & & & & & & & & \\
\hline ATHF & $X$ & & & & & & & & & \\
\hline ECT History & $X$ & & & & & & & & & \\
\hline BDI-II & $\mathrm{X}$ & $\mathrm{X}$ & & & $\mathrm{X}$ & & & $\mathrm{X}$ & $X$ & \\
\hline HRSD-24 & $X$ & & $\mathrm{X}$ & & & $X$ & & & $\mathrm{X}$ & \\
\hline PHQ-9 & $X$ & & $X$ & & & $X$ & & & $\mathrm{X}$ & \\
\hline SSI & $X$ & & $\mathrm{X}$ & & & $X$ & & & $\mathrm{X}$ & \\
\hline WHODAS & $\mathrm{X}$ & & & $\mathrm{X}$ & & & $X$ & & & $X$ \\
\hline
\end{tabular}

Tx: Treatment; MINI: Mini-International Neuropsychiatric Interview; TASS: Transcranial Magnetic Stimulation Adult Safety Screen; ATHF: Antidepressant Treatment History Form; BDI-II: Beck Depression Inventory; HRSD-24: Hamilton Rating Scale for Depression; PHQ-9: Patient Health Questionnaire; SSI: Scale of Suicidal Ideation

\section{rTMS Treatment Parameters}

rTMS treatments will employ the MagPro X100 stimulator (MagVenture, Farum, Denmark) equipped with a B70 fluid-cooled coil. Prior to the first treatment (no more than 5 days prior), each subject's motor threshold (MT) will first be determined according to published methods $(26,27)$. This location, as well as the stimulation target spot, will be marked at the first session on the scalp and standard methods will be used to target this spot during treatment sessions. The modified BeamF3 scalp heuristic will be used to localize the treatment site over the left DLPFC (28). A treatment day will consist of 8 treatment sessions, with the start of each session timed to be at least 50 minutes from the previous session. 
medRxiv preprint doi: https://doi.org/10.1101/2020.12.15.20248260; this version posted December 17, 2020. The copyright holder for this preprint (which was not certified by peer review) is the author/funder, who has granted medRxiv a license to display the preprint in

It is made available under a CC-BY-NC-ND 4.0 International license .

\section{Known Risks and Side Effects}

Tens of thousands of people have received rTMS treatment over the last 20 years. As with any medical procedure, rTMS has certain risks, some of which are known. The known risks associated with rTMS are as follows (percentage of patients experiencing side effect):

- Common: Headache (30\%), discomfort or pain at the stimulation site $(20 \%)$, light headedness or dizziness after the treatment (20\%), facial muscle twitching $(30 \%)$. These side effects are mild and generally diminish over the course of treatment, and can usually be managed with rest, or with over-the-counter pain medications such as acetaminophen or ibuprofen.

- Less Common: (1-7\%) fatigue, headache persisting after the treatment, dizziness or fainting during the initial sessions of rTMS treatment.

- Rare but Serious: Onset of suicidal thinking (less than $1 \%$ ). There is also a $1 \%$ chance that rTMS may lead to a hypomanic episode (the opposite of depression, with symptoms elevated mood and energy, increased activity, impulsiveness, and decreased need for sleep). Participants will be monitored regularly for these symptoms during treatment and will have immediate access to a study psychiatrist if they appear.

- Very Rare but Serious: There are rare cases of an epileptic seizure resulting from rTMS (less than $0.1 \%$ ). Safety guidelines have been in place since 1997 to minimize the risk of seizures from rTMS, and this study follows those guidelines. Still, worldwide, there have been four reports of a seizure during rTMS even when the guidelines were followed. In many of these cases, patients were taking medications known to increase the chances of a seizure occurring spontaneously (29).

Common side effects of rTMS treatment are expected and will be recorded separately from adverse events. If feasible, patients will be asked to defer any medication changes for 4 weeks prior to the treatment course.

We will strongly discourage psychotropic medication initiation or increases other than medication to manage symptomatic burden (i.e. Trazodone or Zopiclone) during the course of rTMS to avoid confounding effects. A visual analog scale ( 0 no pain - 10 worst pain they have experienced) will be used for patients to rate the 
medRxiv preprint doi: https://doi.org/10.1101/2020.12.15.20248260; this version posted December 17, 2020. The copyright holder for this preprint (which was not certified by peer review) is the author/funder, who has granted medRxiv a license to display the preprint in

It is made available under a CC-BY-NC-ND 4.0 International license .

severity of pain from side effects as well as one open ended question asking about other side effects at every visit and after every treatment session. These questions will be completed by the technician so that side effect severity and resolution can be assessed and verified appropriately over time.

\section{Attendance and Withdrawal Criteria}

Patients will be encouraged to attend all scheduled treatments. Those who meet the following criteria will be excluded from the per protocol analysis: If they (1) miss / fail to attend any one of the scheduled treatment days in the course overall; (2) miss / fail to attend more than 5 individual treatment sessions overall; (3) cannot tolerate stimulation at a minimum of $90 \%$ RMT for the entire session on more than 5 treatment sessions overall, as this is likely to lead to inadequate stimulation of the cortex; (4) experience worsening of symptoms warranting an immediate switch to ECT or another intervention, in the clinical opinion of a brain stimulation psychiatrist; (5) withdraw consent to participate; (6) have insufficient response after a minimum of 5 days of treatment and maximum of 16 treatments (i.e. the end of tapering treatments) based on less than $50 \%$ reduction in HRSD-24 or the clinical opinion of the brain stimulation psychiatrist; (7) experience sustained relapse during the relapse prevention phase, as defined by a need for more than two consecutive weeks of twice weekly treatment days. If a participant misses treatment(s) due to a failed COVID-19 screening and are not allowed to enter CAMH or receive treatment, these missed treatment(s) will not count towards discontinuation criteria. In such cases, the study investigators will decide whether treatment will be discontinued.

\section{Eligibility Criteria}

Patients will be included if they: (1) are currently experiencing a unipolar depressive episode based on the MINI with or without psychotic symptoms; (2) have previous response to ECT or high symptom severity warranting acute ECT in the opinion of the brain stimulation psychiatrist; (3) are over the age of 18; (4) pass the TMS adult safety screening (TASS) questionnaire; (5) are voluntary and competent to consent to treatment. 
medRxiv preprint doi: https://doi.org/10.1101/2020.12.15.20248260; this version posted December 17, 2020. The copyright holder for this preprint (which was not certified by peer review) is the author/funder, who has granted medRxiv a license to display the preprint in

It is made available under a CC-BY-NC-ND 4.0 International license .

Patients are excluded if they: (1) have a Mini-International Neuropsychiatric Interview (MINI) confirmed diagnosis of substance dependence or abuse within the last 1 month; (2) have a concomitant major unstable medical illness, cardiac pacemaker or implanted medication pump; (3) have a lifetime Mini-International Neuropsychiatric Interview (MINI) diagnosis of bipolar I or II disorder, schizophrenia, schizoaffective disorder, schizophreniform disorder, delusional disorder; (4) have any significant neurological disorder or insult including, but not limited to: a. any condition likely to be associated with increased intracranial pressure; b. space occupying brain lesion; c. any history of seizure except those therapeutically induced by ECT or a febrile seizure of infancy or single seizure related to a known drug related event; d. cerebral aneurysm; e. significant head trauma with loss of consciousness for greater than 5 minutes; (5) have an intracranial implant (e.g., aneurysm clips, shunts, stimulators, cochlear implants, or electrodes) or any other metal object within or near the head, excluding the mouth, that cannot be safely removed; (6) currently take more than lorazepam $2 \mathrm{mg}$ daily (or equivalent) or any dose of an anticonvulsant due to the potential to limit rTMS efficacy; (7) lack of response to accelerated course of iTBS or rTMS in the past.

\section{Sample Size}

All patients, including both in- and out-patients, referred to the ECT service with MDD with or without psychotic features who are deemed in need of ECT by one of the brain stimulation psychiatrists will be offered information on the trial and will be recorded. If patients do not consent to screening this will be recorded. No personal health information regarding patients who do not consent for screening will be collected. Collecting the number of referrals will allow for an assessment of the impact of the intervention on the entire service as a whole. We estimate that up to 200 patients will be treated with this protocol depending on the duration of the pandemic and the infection control measures instituted.

\section{Data Analysis and Management}

\section{Clinical Outcomes Analysis}

We will assess the number of patients with MDD referred to the service during the pandemic as described above. We will report the number that were able to complete the acute portion of the treatment schedule (up 
medRxiv preprint doi: https://doi.org/10.1101/2020.12.15.20248260; this version posted December 17, 2020. The copyright holder for this preprint (which was not certified by peer review) is the author/funder, who has granted medRxiv a license to display the preprint in

It is made available under a CC-BY-NC-ND 4.0 International license .

to 10 days) on both an outpatient and inpatient basis as a measure of feasibility. Tolerability will be assessed by reporting pain scores and number of withdrawals due to pain or other treatment related adverse events.

Clinical outcomes will be described using descriptive statistics from baseline to post-treatment (paired t-test for continuous and McNemar's chi-square for categorical variables) and will include change in clinical scales. The primary clinical outcome will be the proportion of patients achieving remission on the HRSD-24 (final score $\leq 10$ ) between baseline and end of acute treatment and will be conducted on an intention to treat (ITT) and per protocol basis. Secondary clinical outcomes will include response on the HRSD-24 ( $\geq 50 \%$ reduction in scores) and change from baseline to end of acute treatment. We will repeat these analyses in the same manner for the other clinical scales used. Remission will be defined as scores $\leq 12$ on BDI-II, $<5$ on the GAD-7, $\leq 4$ on the PHQ-9, and SSI $=0$ (if score at baseline is $\geq 1$ ). The change in WHODAS from baseline to end of acute and relapse prevention will also be reported. The proportion of patients maintaining response during relapse prevention will be reported along with number of treatments needed to maintain this response. In addition, the number needing to go on to receive ECT will be reported. Exploratory analyses will include evaluation of demographic and clinical variables associated with response.

\section{Data Management}

The confidentiality of data collected and identity of the individuals participating in this study will be strictly maintained. All files pertaining to subjects in the study will be coded numerically and case report forms (CRFs) will not contain any personal health information. Source documents will be kept in a locked filing cabinet to limit access, and in the case of electronic source documents, files will be password-protected and saved in a secure server. REDCap software will be used for data collection and overall study data management over the course of this project. REDCap is an open-source, web-based clinical data management and electronic data capture system and database and was developed and managed in compliance with HIPAA, PIPEDA, and FDA 21 CFR Part 11 regulations. This system will be used to design electronic case report forms (eCRFs), data entry, data monitoring and cleaning, and for the query and export of datasets for statistical analysis and predictive modeling. 
medRxiv preprint doi: https://doi.org/10.1101/2020.12.15.20248260; this version posted December 17, 2020. The copyright holder for this preprint (which was not certified by peer review) is the author/funder, who has granted medRxiv a license to display the preprint in

It is made available under a CC-BY-NC-ND 4.0 International license .

\section{Discussion}

In summary, current treatment options for patients with TRD suffer from critical deficiencies of efficacy, capacity, or tolerability, especially given the current COVID-19 pandemic. rTMS and aiTBS, in particular, may be able to overcome many of these deficiencies as an approved, safe, well-tolerated, and effective treatment approach. The novel aiTBS protocol described here has the potential to rapidly help patients who otherwise would not be able to or may not want to receive ECT due to concerns regarding cognitive side effects, difficulties with accessibility or time commitment. Further, implementing aiTBS as a treatment for TRD may ultimately reduce the overall burden and need for ECT services, as demand for ECT treatment may exceed capacity during the COVID-19 pandemic. Importantly, shifting an rTMS service to deliver accelerated treatments reduces the number of patients coming into the clinic on a given day, ultimately minimizing exposure and transmission risks to patients. As such, we propose to study aiTBS, including tapering treatments and symptom-based relapse prevention treatments, as a substitute for patients needing ECT during the COVID-19 pandemic.

While several recently published studies have demonstrated that accelerated rTMS can achieve similar outcomes to once daily treatment, in a much shorter timeframe $(19,20,23,24)$, these studies also highlighted the risk of relapse following an acute course of aiTBS. The current study directly addresses the concerns regarding maintaining response and remission with the inclusion of the relapse prevention phase. In addition to potentially providing support for the use of aiTBS in maintaining response rates, we also aim to assess the feasibility, tolerability and clinical utility of aiTBS. An additional strength of this study is the predicted large sample sizes, given the volume of patients with MDD referred to the CAMH brain stimulation service.

The COVID-19 pandemic has resulted in unique challenges for both health care providers and researchers. Ultimately, this has led to a number of important modifications in how research is being conducted as well as several potential limitations. While a definitive assessment of aiTBS would require a randomized shamcontrolled study, the ethical considerations of sham-controlled trials during this pandemic are more complicated than usual. Therefore, we have selected a single group, open-label trial study design. 
medRxiv preprint doi: https://doi.org/10.1101/2020.12.15.20248260; this version posted December 17, 2020. The copyright holder for this preprint (which was not certified by peer review) is the author/funder, who has granted medRxiv a license to display the preprint in

It is made available under a CC-BY-NC-ND 4.0 International license

Furthermore, unlike previous aiTBS protocols $(23,24)$ which include fMRI imaging to localize the treatment site, we will be using the modified BeamF3 scalp heuristic, given that neuroimaging is not feasible during a pandemic. We have also added a number of safety precautions, including virtual screening sessions and weekly assessments, daily symptom screening on site, and enhanced use of personal protective equipment and room cleaning. However, we will likely have to maintain a flexible study protocol to reflect the evolving infection prevention and control recommendations. Additionally, it is to be expected that COVID-19 may impact study recruitment and potentially increase the number of dropouts or missed treatments if patients screen or test positive. While the pandemic has complicated the way in which research is conducted, it is important to continue to adapt to keep rTMS services viable and perform it in the safest manner possible, both for patients and staff.

\title{
Trial status
}

The study is currently recruiting participants. Enrollment of participants started in May 2020.

\begin{abstract}
Abbreviations
aiTBS: accelerated intermittent theta burst stimulation; ATHF: Antidepressant Treatment History Form; BDI-II: Beck's Depression Inventory; CAMH: Centre for Addiction and mental Health; CGI-S and CGI-I: clinician global impression severity and improvement; DLPFC: dorsolateral prefrontal cortex; eCRF: electronic case report forms; ECT: Electroconvulsive therapy; FDA: Food and Drug Administration; fMRI: functional Magnetic Resonance Imaging; GAD-7: Generalized Anxiety Disorder 7-Item; HRSD: Hamilton Rating Scale for Depression; ITT: intention to treat; MDD: Major depressive disorder; MINI: Mini-International Neuropsychiatric Interview; RMT: resting motor threshold; NMS: Neurological, Mental and Substance Use disorders; PHQ-9: Patient Health Questionnaire; RA: research analyst; rTMS: repetitive transcranial magnetic stimulation; SSI: Scale of Suicidal Ideation; STABLE: Symptom-Titrated Algorithm-based Longitudinal ECT; TASS: Transcranial Magnetic Stimulation Adult Safety Screen; TRD: treatmentresistant depression; WHODAS: World Health Organization Disability Assessment Schedule
\end{abstract}

\section{Authors' contributions}

DMB obtained funding and developed the manuscript, with important intellectual input from all co-authors.

\section{Funding}

This work is supported by the Innovation Fund of the Alternative Funding Plan for the Academic Health Sciences Centres of Ontario (grant no. 1000890).

\section{Availability of data and materials}

The final dataset generated from the current protocol will be available from the corresponding author on reasonable request

\section{Ethics approval}

Ethics approval was obtained by the Centre for Addiction and Mental Health Research Ethics Board (reference number 059/2020).

\section{Competing interests}

DMB has received research support from CIHR, NIH, Brain Canada and the Temerty Family through the CAMH 
medRxiv preprint doi: https://doi.org/10.1101/2020.12.15.20248260; this version posted December 17, 2020. The copyright holder for this preprint (which was not certified by peer review) is the author/funder, who has granted medRxiv a license to display the preprint in perpetuity.

It is made available under a CC-BY-NC-ND 4.0 International license

Foundation and the Campbell Family Research Institute. He received research support and in-kind equipment support for an investigator-initiated study from Brainsway Ltd. He is the site principal investigator for three sponsor-initiated studies for Brainsway Ltd. He also receives in-kind equipment support from Magventure for investigator-initiated research. He received medication supplies for an investigator-initiated trial from Indivior.

FVR receives research support from Canadian Institutes of Health Research, Brian Canada, Michael Smith Foundation for Health Research, Vancouver Coastal Health Research Institute, and in-kind equipment support for investigatorinitiated trial from MagVenture. He has participated in an advisory board for Janssen.

JD has received research support from the Arrell Family Foundation, the Buchan Family Foundation, Brain Canada, the Canadian Biomarker Integration Network in Depression, the Canadian Institutes of Health Research (CIHR), the Klarman Family Foundation, NIH, the Ontario Brain Institute, the Toronto General and Western Hospital Foundation, and the Weston Family Foundation; he has received travel stipends from Lundbeck and ANT Neuro; he has served as an advisor for BrainCheck, Restorative Brain Clinics, and TMS Neuro Solutions.

ZJD has received research support from the Ontario Mental Health (OMH) Foundation, the CIHR, the Brain and Behaviour Research Foundation, and the Temerty family and Grant family through the CAMH Foundation and the Campbell Institute. ZJD has received research and equipment in-kind support for an investigator-initiated study through Brainsway Inc., and a travel allowance through Merck. ZJD has also received speaker funding through Sepracor Inc., and AstraZeneca, served on advisory boards for Hoffmann-La Roche Limited and Merck, and received speaker support from Eli Lilly. DBL, MG, TK, YK, GK, APT, DV and CRW report no competing interests. 
medRxiv preprint doi: https://doi.org/10.1101/2020.12.15.20248260; this version posted December 17, 2020. The copyright holder for this preprint (which was not certified by peer review) is the author/funder, who has granted medRxiv a license to display the preprint in

It is made available under a CC-BY-NC-ND 4.0 International license .

\section{References}

1. Association AP. Diagnostic and statistical manual of mental disorders. 5th ed. Arlington, Vermont: American Psychiatric Publishing; 2013.

2. Organization WH. The global burden of disease: 2004 update. Geneva: WHO; 2008.

3. Rossi S, Hallett M, Rossini PM, Pascual-Leone A, Avanzini G, Bestmann S, et al. Safety, ethical considerations, and application guidelines for the use of transcranial magnetic stimulation in clinical practice and research. Clin Neurophysiol. 2009;120(12):2008-39.

4. Souery D, Amsterdam J, de Montigny C, Lecrubier Y, Montgomery S, Lipp O, et al. Treatment resistant depression: methodological overview and operational criteria. European neuropsychopharmacology : the journal of the European College of Neuropsychopharmacology. 1999;9(1-2):83-91.

5. Spaans HP, Verwijk E, Comijs HC, Kok RM, Sienaert P, Bouckaert F, et al. Efficacy and cognitive side effects after brief pulse and ultrabrief pulse right unilateral electroconvulsive therapy for major depression: a randomized, double-blind, controlled study. J Clin Psychiatry. 2013;74(11):e1029-36.

6. Sackeim HA, Prudic J, Nobler MS, Fitzsimons L, Lisanby SH, Payne N, et al. Effects of pulse width and electrode placement on the efficacy and cognitive effects of electroconvulsive therapy. Brain Stimul. 2008;1(2):71-83.

7. Sackeim HA, Prudic J, Fuller R, Keilp J, Lavori PW, Olfson M. The cognitive effects of electroconvulsive therapy in community settings. Neuropsychopharmacol. 2007;32(1):244-54.

8. Ingram A, Saling MM, Schweitzer I. Cognitive side effects of brief pulse electroconvulsive therapy: a review. J ECT. 2008;24(1):3-9.

9. Brakemeier EL, Berman R, Prudic J, Zwillenberg K, Sackeim HA. Self-evaluation of the cognitive effects of electroconvulsive therapy. J ECT. 2011;27(1):59-66.

10. Bustin J, Rapoport MJ, Krishna M, Matusevich D, Finkelsztein C, Strejilevich S, et al. Are patients' attitudes towards and knowledge of electroconvulsive therapy transcultural? A multinational pilot study. Int J Geriatr Psychiatry. 2008;23(5):497-503.

11. Weir D. The media's damaging impact on public perception of electroconvulsive therapy 2013 [Available from: http://healthydebate.ca/opinions/the-medias-damaging-impact-on-publicperception-of-electroconvulsive-therapy.

12. Rossi S, Hallett M, Rossini PM, Pascual-Leone A. Safety, ethical considerations, and application guidelines for the use of transcranial magnetic stimulation in clinical practice and research. Clin Neurophysiol. 2009;120(12):2008-39.

13. Downar J, Geraci J, Salomons TV, Dunlop K, Wheeler S, McAndrews MP, et al. Anhedonia and Reward-Circuit Connectivity Distinguish Nonresponders from Responders to Dorsomedial Prefrontal Repetitive Transcranial Magnetic Stimulation in Major Depression. Biol Psychiatry. 2013.

14. Lipsman N, Sankar T, Downar J, Kennedy SH, Lozano AM, Giacobbe P. Neuromodulation for treatment-refractory major depressive disorder. CMAJ : Canadian Medical Association journal = journal de l'Association medicale canadienne. 2014;186(1):33-9.

15. Hallett M. Transcranial magnetic stimulation: a primer. Neuron. 2007;55(2):187-99.

16. O'Reardon JP, Solvason HB, Janicak PG, Sampson S, Isenberg KE, Nahas Z, et al. Efficacy and safety of transcranial magnetic stimulation in the acute treatment of major depression: a multisite randomized controlled trial. Biological psychiatry. 2007;62(11):1208-16.

17. Blumberger DM, Vila-Rodriguez F, Thorpe KE, Feffer K, Noda Y, Giacobbe P, et al. Effectiveness of theta burst versus high-frequency repetitive transcranial magnetic stimulation in patients with depression (THREE-D): a randomised non-inferiority trial. Lancet.

2018;391(10131):1683-92. 
medRxiv preprint doi: https://doi.org/10.1101/2020.12.15.20248260; this version posted December 17, 2020. The copyright holder for this preprint (which was not certified by peer review) is the author/funder, who has granted medRxiv a license to display the preprint in

It is made available under a CC-BY-NC-ND 4.0 International license .

18. Di Lazzaro V, Dileone M, Pilato F, Capone F, Musumeci G, Ranieri F, et al. Modulation of motor cortex neuronal networks by rTMS: comparison of local and remote effects of six different protocols of stimulation. Journal of neurophysiology. 2011;105(5):2150-6.

19. Holtzheimer PE, 3rd, McDonald WM, Mufti M, Kelley ME, Quinn S, Corso G, et al. Accelerated repetitive transcranial magnetic stimulation for treatment-resistant depression. Depress Anxiety. 2010;27(10):960-3.

20. Hadley D, Anderson BS, Borckardt JJ, Arana A, Li X, Nahas Z, et al. Safety, tolerability, and effectiveness of high doses of adjunctive daily left prefrontal repetitive transcranial magnetic stimulation for treatment-resistant depression in a clinical setting. J ECT. 2011;27(1):18-25.

21. McGirr A, Van den Eynde F, Tovar-Perdomo S, Fleck MP, Berlim MT. Effectiveness and acceptability of accelerated repetitive transcranial magnetic stimulation (rTMS) for treatmentresistant major depressive disorder: an open label trial. J Affect Disord. 2015;173:216-20.

22. Baeken C, Vanderhasselt MA, Remue J, Herremans S, Vanderbruggen N, Zeeuws D, et al. Intensive HF-rTMS treatment in refractory medication-resistant unipolar depressed patients. J Affect Disord. 2013;151(2):625-31.

23. Cole EJ, Stimpson KH, Bentzley BS, Gulser M, Cherian K, Tischler C, et al. Stanford Accelerated Intelligent Neuromodulation Therapy for Treatment-Resistant Depression. Am J Psychiatry. 2020:appiajp201919070720.

24. Williams NR, Sudheimer KD, Bentzley BS, Pannu J, Stimpson KH, Duvio D, et al. Highdose spaced theta-burst TMS as a rapid-acting antidepressant in highly refractory depression. BRAIN. 2018;141:1-5.

25. Lisanby SH, Sampson S, Husain MM, Petrides G, Knapp RG, McCall V, et al. Toward individualized post-electroconvulsive therapy care: piloting the Symptom-Titrated, AlgorithmBased Longitudinal ECT (STABLE) intervention. J ECT. 2008;24(3):179-82.

26. Schutter DJ, van Honk J. A standardized motor threshold estimation procedure for transcranial magnetic stimulation research. J ECT. 2006;22(3):176-8.

27. Julkunen P, Saisanen L, Sarasti M, Kononen M. Effect of electrode cap on measured cortical motor threshold. Journal of neuroscience methods. 2009;176(2):225-9.

28. Mir-Moghtadaei A, Caballero R, Fried P, Fox MD, Lee K, Giacobbe P, et al. Concordance Between BeamF3 and MRI-neuronavigated Target Sites for Repetitive Transcranial Magnetic Stimulation of the Left Dorsolateral Prefrontal Cortex. Brain Stimulation. 2015;8(5):965-73. 29. Dobek CE, Blumberger DM, Downar J, Daskalakis ZJ, Vila-Rodriguez F. Risk of seizures in transcranial magnetic stimulation: a clinical review to inform consent process focused on bupropion. Neuropsychiatr Dis Treat. 2015;11:2975-87. 